\title{
Stilbene-Based Two-Photon Thermo- Solvatochromic Fluorescence Probes with Large Two-Photon Absorption Cross Sections and Two- Photon Triple Fluorescence: Detection of Solvent Polarities, Viscosities, and Temperature
}

\author{
Chi Bao Huang*, Xiao Jun Peng and Jiang Li Fan \\ Department of Agricultural Engineering, Dalian University of Technology, China \\ *Corresponding author: Chi Bao Huang, Department of Agricultural Engineering, Dalian University of Technology, China. \\ To Cite This Article: Chi Bao Huang. Stilbene-Based Two-Photon Thermo-Solvatochromic Fluorescence Probes with Large Two-Photon \\ Absorption Cross Sections and Two-Photon Triple Fluorescence: Detection of Solvent Polarities, Viscosities, and Temperature. Am J Biomed Sci \\ \& Res. 2019 - 4(2). AJBSR.MS.ID.000778. DOI: 10.34297/AJBSR.2019.04.000778
}

Received: May 10, 2019 | Published: July 24, 2019

\begin{abstract}
The unusually sensitive solvatochromism of 2,5-dicyano-4-methyl-4'-dimethylaminostilbene (P1) whose emission maximum varies from 445 $\mathrm{nm}$ in cyclohexane to $641 \mathrm{~nm}$ in DMSO are described. 1a with remarkably large two-photon cross sections exhibits very strong polarity-, viscosity-, and temperature-dependence of fluorescence, and can be used to detect polarities, viscosities, and temperature. The successful application of P1 provides a brilliant prototype for the developments of ideal two-photon fluorescence probes.
\end{abstract}

Keywords: Two photons; Two photon fluorescence; Two photon absorption; Dicyano 4 amino stilbene; Donor $\pi$ acceptor; Hydrogen bonding donor; Non hydrogen bonding donor; Localized excited state; Internal charge transfer

\section{Introduction}

For the development of two-photon (TP) fluorescence (TPF)optimized molecular probes, it is important to have a significant modulation of the photophysical properties of the chromophore in response to external stimuli, such as polarity, $\mathrm{pH}$, ion concentration, and temperature. At the same time, the chromophore should retain a significant two-photon absorption (TPA) cross section $(\delta)$ in a suitable excitation window for biological imaging (700-1000 nm, corresponding to an optimum combination of reduced scattering and absorption in biological samples). In contrast to PET-based fluorescence probes, which only show increasing or decreasing emission intensity at fixed wavelength, solvatochromic probes may indicate the presence of an analyte by a significant change of emission wavelength [1] which is unequivocally detectable. Although a small number of TPF probes for polarity were reported [2,3] and two among them were used for lipid rafts imaging [3] their applications can't be extended from polarity detection to viscosities and temperature. Furthermore, in them, small molecule- size always be accompanied by narrow solvatochromic range and small $\delta$. So, they are not ideal candidates for TP solvatochromic probes $[4,5]$.

An ideal TP solvatochromic probe should have wide solvatochromic range, small molecule-size, large $\delta$ and excellent photostability. Herein, we report two TP solvatochromic probes (P1 and P2) derived from 4-methyl-2,5-dicyano-4'-amino stilbene (DCS) with remarkably large $\delta$, which has been successfully employed in the design of TPF probes for metal ions.4 DCS is a pushpull chromophore with a donor- $\pi$-acceptor (D- $\pi-A$ ) architecture. It is studied that these two probes are applied to the detection of solvent polarities, viscosities and temperature, especially twophoton triple fluorescence is found for the first time.

The absorption properties of P1 are almost independent on the solvent (Table 1). 


\begin{tabular}{|c|c|c|c|c|c|}
\hline Solvent ${ }^{\mathrm{a}}$ & $\lambda_{\max }^{\mathrm{b}}$ & $\lambda_{\max } \mathrm{c}$ & $\Phi^{d}$ & $\lambda_{\max } \mathrm{e}$ & $\boldsymbol{\delta}_{\max }^{\mathrm{f}}$ \\
\hline c-hexane & 410 & 451 & 0.805 & 810 & 6670 \\
\hline toluene & 416 & 458 & 0.814 & 810 & 3610 \\
\hline benzene & 416 & 486 & 0.846 & 840 & 4650 \\
\hline dioxane & 410 & 507 & 0.885 & 810 & 4230 \\
\hline THF & 407 & 539 & 0.763 & 810 & 3720 \\
\hline $\mathrm{CHCl} 3$ & 419 & 537 & 0.745 & 840 & 2860 \\
\hline acetone & 413 & 578 & 0.265 & 800 & 1790 \\
\hline DMF & 405 & 595 & 0.106 & 800 & 1450 \\
\hline DMSO & 410 & 603 & 0.066 & 800 & 1980 \\
\hline $\mathrm{MeCN}$ & 401 & 599 & 0.058 & 800 & 2040 \\
\hline
\end{tabular}

a Solvents arranged in order of decreasing $E_{\mathrm{T}}(30)$ value. ${ }^{\mathrm{b}}$ Absorption maximum with the lowest energy in $\mathrm{nm}, \mathrm{C}(\mathrm{P} 1)=10^{-5} \mathrm{M}$. ${ }^{\mathrm{c}} \mathrm{Emission}$ maximum in $\mathrm{nm}, \mathrm{c}(\mathrm{P} 1)=10^{-5} \mathrm{M}, \lambda \mathrm{ex}=410 \mathrm{~nm}$. ${ }^{\mathrm{d}}$ Relative to quinine sulfate $10^{-6} \mathrm{M}$ in $0.05 \mathrm{~mol} \mathrm{~L}^{-1} \mathrm{H} 2 \mathrm{SO} 4$; estimated error, $\pm 10 \%$ of the given values. ${ }^{\mathrm{e}}$ Two-photon excitation maximum in $\mathrm{nm} .{ }^{\mathrm{f}}$ the peak TPA cross-sections in $10^{-50} \mathrm{~cm}^{4} \mathrm{~s} /$ photon / GM.

However, with respect to the emission properties, P1 exhibits an unexpected strong solvatochromism. Only a few previous examples of solvatochromic behaviour for stilbene derivatives [5] which just possess one substituent at most in the single aromatic ring and are not ideal candidates for solvatochromic probes had been reported. Thus, the emission maximum (EM) for P1 (P2) varies from 445 (452) $\mathrm{nm}$ in cyclohexane to 641 (604) $\mathrm{nm}$ in DMSO. The reason why the solvatochromic shifts of P2 are somewhat smaller (ca. $156 \mathrm{~nm}, \mathrm{cf}$. SI) is that both decreasing transition energy and increasing sensitivity to solvent polarity for the weak electron donor diphenylamino group are inferior to ones for the strong electron donor dimethylamine group (Table 1) (Figure 1,9 \& 17).
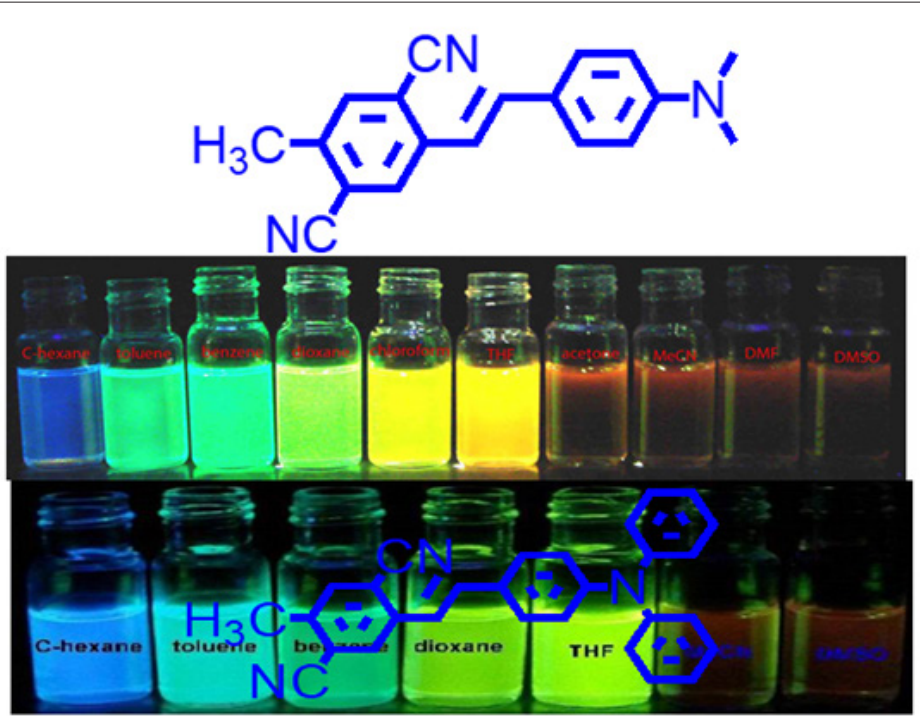

Figure 1: Picture of fluorescence of $1 \mathrm{a}$ and $1 \mathrm{~b}\left(\mathrm{c}=10^{-5} \mathrm{M}, \lambda_{\mathrm{ex}}=365 \mathrm{~nm}\right)$ in different solvents.

Protic solvents (Hydrogen-Bonding-Donor, HBD) can interact with the donor (dimethylamino) for the ground state of P1 to stabilize the ground state more than the excited state, and thus, lower energy for the ground state results in a relative blue shift as compared with strong polar aprotic solvents (Non-HydrogenBonding-Donor, NHD). The fitting between EM in wavenumbers and the solvent parameters such as the $\mathrm{E}_{\mathrm{T}}(30)$ data [6] the Kosower parameter, $\mathrm{Z}$, the Gibbs energy of activation of the solvolysis $(\delta \Delta \mathrm{G} \neq)$ [6], the index of solvent dipolarity/polarizability ( $\left.\pi^{*}\right)$ [7] and the Lippert-Mataga scale $(\Delta \mathrm{f})$ [8] gave an almost linear relationship $\left(\mathrm{r}^{2}\right.$ $=0.90,0.90,0.90,0.85,0.82$, respectively).
In one- and two-photon emissions (OPE and TPE), band A $\left({ }^{1} \mathrm{~L}_{\mathrm{a}}\right)$ of P1 in glycerol all shift to the red with increasing temperature, and the relative intensities of band $B\left({ }^{1} L_{b}\right)$ gradually decreases (Figure 2). The viscosity dependence of the fluorescence for P1 exhibits differences between A band and B band, and between OPE and TPE (Figure 3). The intensities of B band in OPE and TPE steadily increase upon the augment of viscosities, whereas the intensities of A band in TPE at first rapidly decline, and then enhance, and a third band at $542 \mathrm{~nm}$, namely exciplex (E) fluorescence from strong intermolecular donor-acceptor systems [9] finally disappears in pure glycerol (Figure 3). Never has this property in two-photon been 
reported. High viscosity preventing intermolecular charges from transfer should be responsible for the disappearance of the third band whose no emergence in the OPE possibly consists in its low intensity and short lifetime. In addition, at the low concentration (10 ${ }^{6} \mathrm{M}$ ) of $\mathrm{P} 1$, the intensity ratio (IR) $\mathrm{I}_{\mathrm{a}} / \mathrm{I}_{\mathrm{b}}$ of the emission bands $\mathrm{A}$ and $\mathrm{B}$ decreases with increasing viscosity, but at the high concentration (3 $\times 10^{-6} \mathrm{M}$ ) the IR $I_{a} / I_{b}$ increases, irrespective of OPE and TPE (cf. SI).
Furthermore, the concentration dependence [10] is found for the IR Ia/Ib of the emission bands A and B of P1 in alcohol (cf. SI). The above environmental influences upon triple fluorescence bands A, $\mathrm{B}$ and $\mathrm{E}$ usually indicate three emissive species, i.e., the localized excited state (LE), a twisted intramolecular charge transfer state (TICT) and an intermolecular exciplex [11].
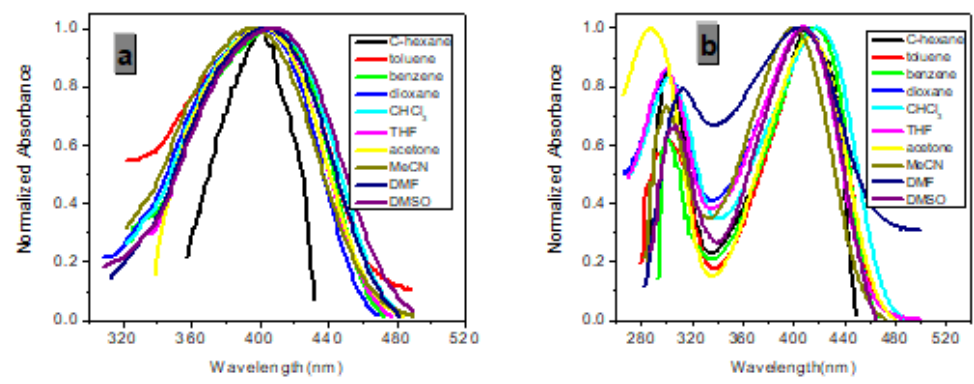

Figure 2: Normalized absorption spectra of $1 \mathrm{a}(\mathrm{a})$ and $1 \mathrm{~b}(\mathrm{~b})\left(\mathrm{c}=10^{-5} \mathrm{M}\right)$ in various solvents.
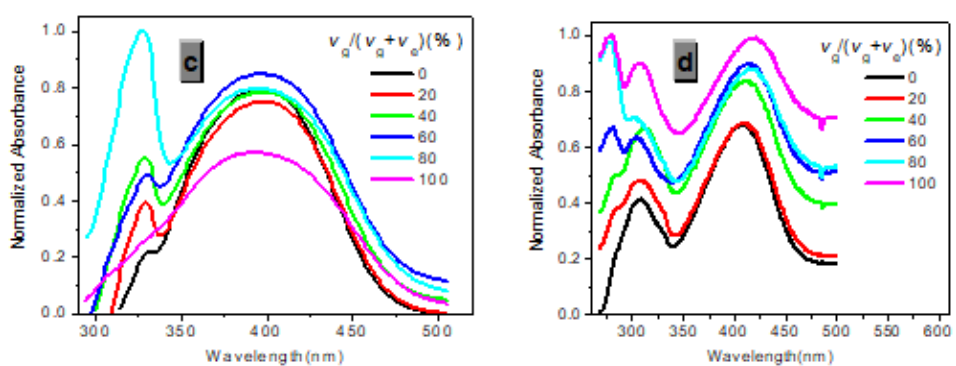

Figure 3: Normalized absorption spectra of $1 \mathrm{a}(\mathrm{c})$ and $1 \mathrm{~b}(\mathrm{~d})\left(\mathrm{c}=10^{-5} \mathrm{M}\right)$ in glycerol-ethanol $\left(\mathrm{v}_{\mathrm{g}} /\left(\mathrm{v}_{\mathrm{g}}+\mathrm{v}_{\mathrm{e}}\right), \%\right)$.

As expected, ${ }^{\delta} \mathrm{TPA}$ of P1 climbs its maximum of $5560 \mathrm{GM}$ in nonpolar cyclohexane, while in strongly polar aprotic DMF it falls to its minimum of $130 \mathrm{GM}$. In general, ${ }^{\delta} \mathrm{TPA}$ of P1 are much larger in low polarity aprotic solvents than in high polarity aprotic solvents, which should be attributed to the excited state configuration transformation (Table 1). The reduction in emission intensity for P1 in acetone and other more polar solvents together with a near lack of photo reactivity is certainly consistent with decay of the emissive state to one or more of the possible noncop-lanar and no emissive TICT which subsequently decay rapidly to the ground state [5c] (Figure $7 \& 22$ ).

As in other solvatochromic systems [12], an internal charge transfer (ICT) due to a strong donor-acceptor interplay between the dimethylamino and the 2,5-dicyano-4-methyl stilbyl moieties can take place in the excited state of P1. On one hand, ortho- and meta-cyano groups of double bonds $(\mathrm{C}=\mathrm{C})$ are fairly strong electron acceptor in the ground state, which can remarkably decrease transition energy, stabilize resonance structures and increase both the excited state dipole moment and molecular sensitivity to solvent polarity. On the other hand, these two cyano groups can notably extend conjugated system, which consumedly improves ${ }^{\delta} \mathrm{TPA}$ and the fluorescence quantum yield. Additionally, in the excited state, the adiabatic ICT leads to an intermediate that most likely develops a negative charge for the nitrogen atom of the ortho- cyano group, that is, after solvent relaxation $[6,12,13]$ stabilized not only by polar solvents, especially those with high $\pi^{*}$, but also by the meta-cyano group with strong electron-withdrawing capacity for greater diffusion of the concentrated negative charge. This ICTsolvent relaxation sequence explains the significant red shift of the emission spectra in polar solvents as well as the temperature and viscosity dependence of the emission properties $[6,13]$.

\section{Materials and Methods}

NMR spectra were recorded on a VARIAN INOVA $400 \mathrm{MHz}$ NMR spectrometer. Mass spectral determinations were made on a Q-TOF mass spectrometry (Micro mass, England). High resolution mass spectra measurements were performed at a GC-TOF mass spectrometry (Micromass, US) (Electron Ionization source). Fluorescence measurements were performed on a PTI-C-700 Felix and Time-Master system. Fluorescence quantum yields were measured using standard methods on air-equilibrated samples at room temperature. Quinine bisulphate in $0.05 \mathrm{M} \mathrm{H}_{2} \mathrm{SO}_{4}(\Phi=0.546)$ was used as a reference [14].

TPEF (two-photon-excited fluorescence) action cross-section spectra were measured according to the experimental protocol established by Xu and Webb [15] using a mode-locked Ti/sapphire laser that delivers $\sim 80 \mathrm{fs}$ pulses at $80 \mathrm{MHz}$. Fluorescein $\left(10^{-4} \mathrm{M}\right.$ 
in $0.1 \mathrm{M} \mathrm{NaOH}$ ), whose TPEF action cross-sections are well-known [15] served as the reference. The quadratic dependence of the fluorescence intensity on the excitation intensity was verified for each data point, indicating that the measurements were carried out in intensity regimes in which saturation or photodegradation do not occur. The measurements were performed at room temperature on air-equilibrated solutions $\left(10^{-5} \mathrm{M}\right)$. The experimental uncertainty on the absolute action cross-sections determined by this method has been estimated to be $\pm 20 \%$. Absorption spectra were measured on a HP-8453 spectrophotometer. Solvents were generally dried and distilled prior to use. Reactions were monitored by thin-layer chromatography on Merck silica gel $60 \mathrm{~F}_{254}$ precoated aluminium sheets. Column chromatography: Merck silica gel Si 60 (40-63 $\mu \mathrm{m}$, 230-400 mesh).

\section{Syntheses}

2,5-dibromo-p-xylene (3),[16] 2,5-dimethyl-terephthalonitrile (4), 4-(N, N-diphenyl amino) benzaldehyde, [17] were synthesized according to literature procedures. (syntheses).

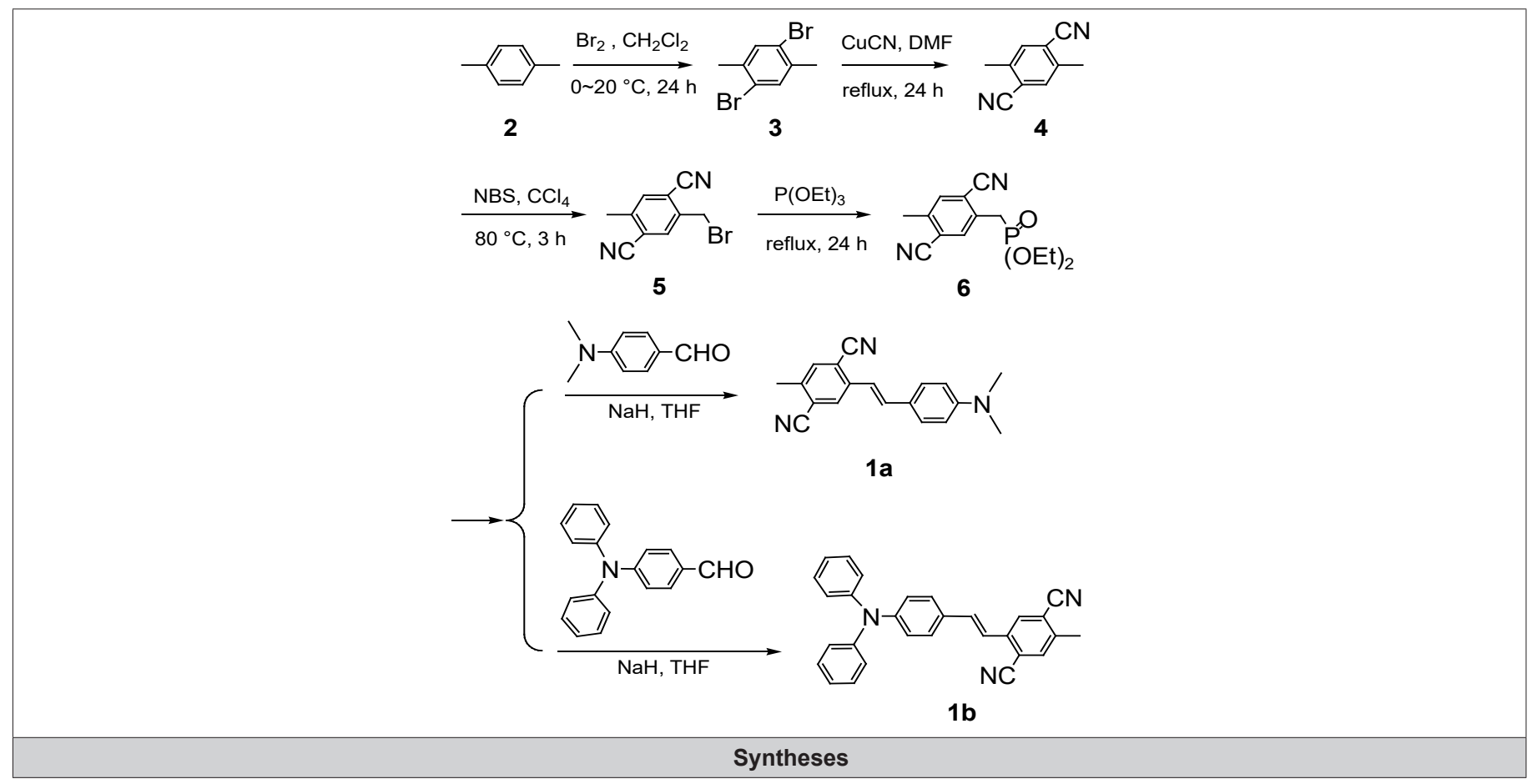

\section{2-Bromomethyl-5-methyl-terephthalonitrile (5)}

2,5-dimethyl-terephthalonitrile (4) (2.0 g, $13 \mathrm{mmol}), \mathrm{N}$-bromosuccinimide (NBS) (2.3 g, $13 \mathrm{mmol}$ ), benzoyl peroxide (BPO) $(0.1$ g) and $\mathrm{CCl}_{4}(100 \mathrm{~mL})$ were placed into a $250 \mathrm{~mL}$ flask, the mixture was refluxed for $2 \mathrm{~h}$. After cooled to room temperature, the mixture was filtered, and the filtrate was concentrated by evaporating the solvent to get a viscous liquid. Flash chromatography on silica gel (20:1 $\mathrm{CH}_{2} \mathrm{Cl}_{2}: \mathrm{n}$-hexane) yielded the product as a white powder (1.9 g, 62\%). ${ }^{1} \mathrm{H}$ NMR $\left(\mathrm{CDCl}_{3}, 400 \mathrm{MHz}\right) \delta: 7.788(\mathrm{~s}, 1 \mathrm{H}), 7.637(\mathrm{~s}, 1 \mathrm{H})$, 4.594 (s, 2H), 2.604 (s, 3H). HS-MS (EI) m/z: 233.9747 (calcd for $\mathrm{C}_{10} \mathrm{H}_{7} \mathrm{BrN}_{2}: 233.9793$ ).

\section{(2,5-dicyano-4-methylbenzyl)-phosphonic acid diethyl ester (6)}

A solution of 2-Bromomethyl-5-methyl-terephthalonitrile (5) $(1.4 \mathrm{~g}, 6 \mathrm{mmol})$ and $\mathrm{P}(\mathrm{OEt})_{3}(2.5 \mathrm{~g}, 15 \mathrm{mmol})$ in $10 \mathrm{~mL}$ toluene were heated to $120^{\circ} \mathrm{C}$ for $5 \mathrm{~h}$. Excess $\mathrm{P}(\mathrm{OEt})_{3}$ was removed in vacuo. Flash chromatography on silica gel $\left(1: 1 \mathrm{CH}_{2} \mathrm{Cl}_{2}\right.$ : ethyl acetate) yielded the product as a white crystalline solid (1.7 g, 98\%). ${ }^{1} \mathrm{H} \mathrm{NMR}\left(\mathrm{CDCl}_{3}, 400\right.$ MHz) $\delta: 7.758(\mathrm{~d}, \mathrm{~J}=2.8 \mathrm{~Hz}, 1 \mathrm{H}), 7.619(\mathrm{~s}, 1 \mathrm{H}), 4.133(\mathrm{~m}, 4 \mathrm{H}), 3.377$ (d, J=22 Hz, 2H), 2.580 (s, 3H), 1.312 (t, J=7.2 Hz, 6H). 13C NMR $\left(\mathrm{CDCl}_{3}, 400 \mathrm{MHz}\right) \delta: 141.267,134.723,134.662,134.283,117.416$,
116.391, 62.929, 62.861, 32.672, 31.298, 20.102, 16.527, 16.466. HS-MS (EI) m/z: 292.0977 (calcd for $\mathrm{C}_{14} \mathrm{H}_{17} \mathrm{~N}_{2} \mathrm{O}_{3} \mathrm{P}: 292.0977$ ).

\section{2,5-dicyano-4-methyl-4'-(dimethylamino) stilbene (1a).}

Dimethylaminobenzaldehyde (170 mg, $1.14 \mathrm{mmol}$ ), and $\mathrm{NaH}$ (55 mg $2.28 \mathrm{mmol}$ ) were dissolved in $10 \mathrm{~mL}$ of tetrahydrofuran (THF), and the solution was cooled to $0^{\circ} \mathrm{C}$. To this solution, (2,5-dicyano-4-methylbenzyl)-phosphonic acid diethyl ester (6) (333 mg, $1.14 \mathrm{mmol}$ ) in $10 \mathrm{~mL}$ of THF was added dropwise, and the reaction mixture was stirred for $12 \mathrm{~h}$ at $0^{\circ} \mathrm{C}$. Water was added to the reaction mixture, and the product was extracted with ethyl acetate [16]. The organic layer was dried with $\mathrm{MgSO}_{4}$ followed by evaporation of the solvent. The crude product was separated by column chromatography with a gradient of hexane in dichloromethane (20-0\%) and ethyl acetate in dichloromethane (0$20 \%)$. The resulting solid was recrystallized from acetone to give yellow powder (212 mg, $0.74 \mathrm{mmol}, 65 \%$ in yield). m.p. $256-257^{\circ} \mathrm{C}$. ${ }^{1} \mathrm{H} \mathrm{NMR}\left(\mathrm{CDCl}_{3}, 400 \mathrm{MHz}\right) \delta: 7.969$ (s, 1H), 7.534 (s, 1H), 7.472(d, $\mathrm{J}=9.2 \mathrm{~Hz}, 2 \mathrm{H}$ ), 7.211 (d, J=16 Hz, 1H), 7.128 (d, J=16 Hz, 1H), 6.725 (d, J=8.4 Hz, 2H), 3.030 (s, 6H), 2.546 (s, 3H) . 13C NMR (CDCl3, 400 MHz) $\delta: 140.075,139.050,135.171,134.404,128.939,128.802$, $117.477,117.105,116.991,113.902,112.497,40.567,20.056$. HSMS (EI) $m / z$ : 287.1326 (calcd for $\mathrm{C}_{19} \mathrm{H}_{17} \mathrm{~N}_{3}: 287.1422$ ). 


\section{2,5-dicyano-4-methyl-4'-(diphenylamino) stilbene (1b).}

It is prepared by similar procedures given above for 1a [17]. The crude product was purified by column chromatography on silica gel with dichloromethane-acetone $(7: 2)$ as eluent to give $1 \mathrm{~b}$ in $62 \%$ yield as a green crystal. m.p. $213-214{ }^{\circ} \mathrm{C} .{ }^{1} \mathrm{H}$ NMR $\left(\mathrm{CDCl}_{3}\right.$, $400 \mathrm{MHz}$ ) $\delta: 7.977$ (s, 1H), $7.567(\mathrm{~s}, 1 \mathrm{H}), 7.424$ (d, J=7.6 Hz, 2H), $7.310 \sim 7.258(\mathrm{~m}, 5 \mathrm{H}), 7.234(\mathrm{~d}, \mathrm{~J}=19.6 \mathrm{~Hz}, 1 \mathrm{H}), 7.120$ (d, J=16.4 Hz, 1H), $7.121 \sim 7.039$ (m, 5H), 2.565 (s, 3H) [13]. C NMR ( $\mathrm{CDCl}_{3}, 400$
MHz): $\delta: 147.271,139.893,139.521,134.617,134.496,129.622$, $129.129,128.484,125.303,123.937,122.570,1119.731,117.598$ 116.885, 114.387, 20.132. HS-MS (EI) $m / z: 411.1697$ (calcd for $\left.\mathrm{C}_{29} \mathrm{H}_{21} \mathrm{~N}_{3}: 411.1735\right)$.

\section{Spectroscopy Data}

See the following figures (Figure 1-22)
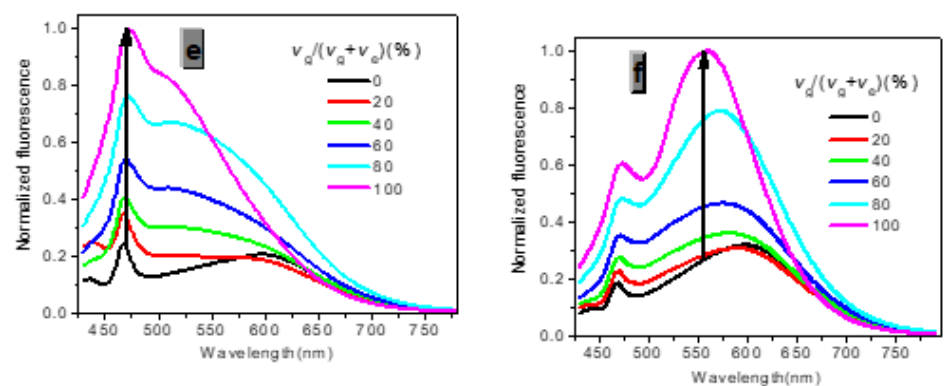

Figure 4: Normalized one-photon emission spectra of $1 a\left((e) c=10^{-6} M\right.$, (f) $\left.c=3 \times 10^{-6} M, \lambda_{e x}=410 \mathrm{~nm}\right)$ in glycerol-ethanol $\left(v_{g} /\left(v_{g}+v_{e}\right), \%\right)$.
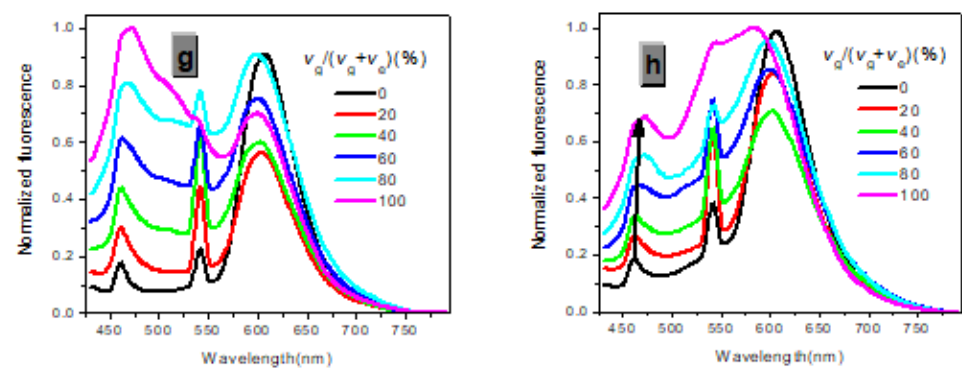

Figure 5: Normalized two-photon emission spectra of $1 \mathrm{a}\left((\mathrm{g}) \mathrm{c}=10^{-6} \mathrm{M},(\mathrm{h}) \mathrm{c}=3 \times 10^{-6} \mathrm{M}, \lambda \mathrm{ex}=790 \mathrm{~nm}\right)$ in glycerol-ethanol $\left(\mathrm{v}_{\mathrm{g}} /\left(\mathrm{v}_{\mathrm{g}}+\mathrm{v}_{\mathrm{e}}\right)\right.$, \%).
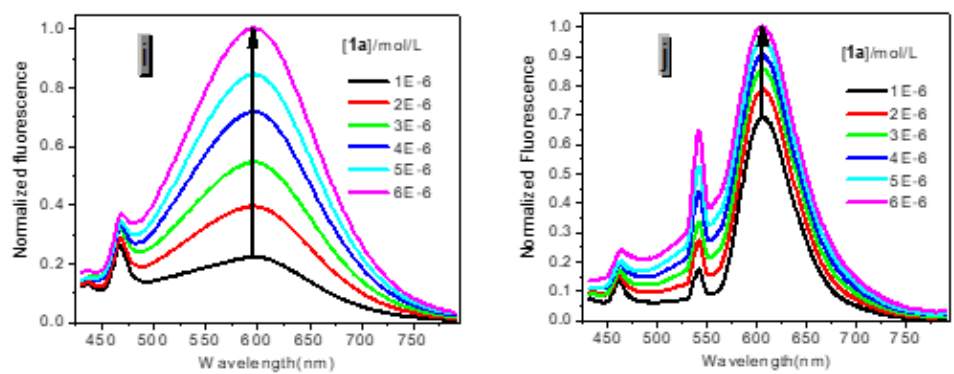

Figure 6: Normalized (i) one- $\left(\lambda_{\mathrm{ex}}=410 \mathrm{~nm}\right)$ and (j) two-photon $\left(\lambda_{\mathrm{ex}}=790 \mathrm{~nm}\right)$ emission spectra of 1a in ethanol versus its concentrations.
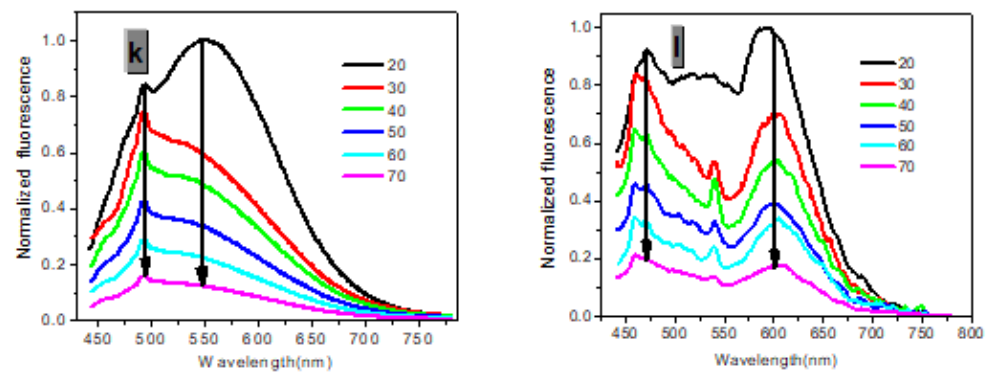

Figure 7: Normalized $(\mathrm{k})$ one- $\left(\lambda_{\mathrm{ex}}=410 \mathrm{~nm}\right)$ and $(\mathrm{l})$ two-photon $\left(\lambda_{\mathrm{ex}}=790 \mathrm{~nm}\right)$ emission spectra of $1 \mathrm{a}\left(\mathrm{c}=10^{-6} \mathrm{M}\right)$ in glycerol versus temperature $\left({ }^{\circ} \mathrm{C}\right)$ 


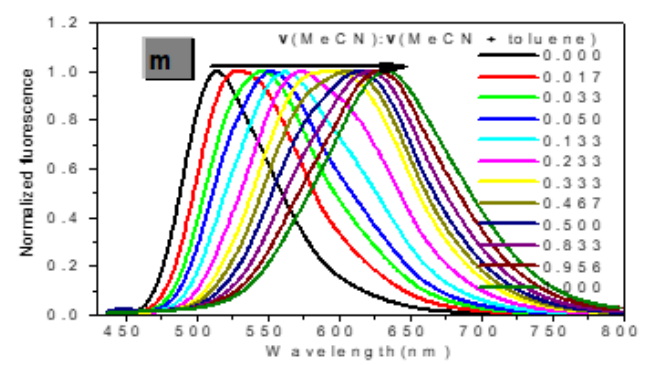

Figure 8: Normalized one-photon emission spectra of $1 \mathrm{a}\left(\mathrm{c}=10^{-5} \mathrm{M}, \lambda_{\mathrm{ex}}=410 \mathrm{~nm}\right)$ in toluene-MeCN mixture versus MeCN concentrations.

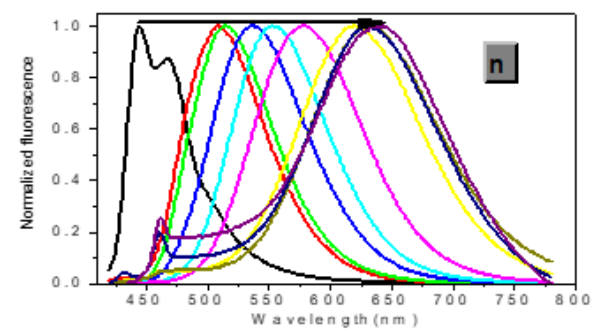

Figure 9: Normalized two-photon emission spectra (left to right: C-hexane, toluene, benzene, dioxane, $\mathrm{CHCl}_{3}$, $\mathrm{THF}$, acetone, MeCN, DMF, DMSO) of $1 \mathrm{a}\left(\mathrm{c}=10^{-5} \mathrm{M}, \lambda_{\mathrm{ex}}=790 \mathrm{~nm}\right)$ in various solvents.

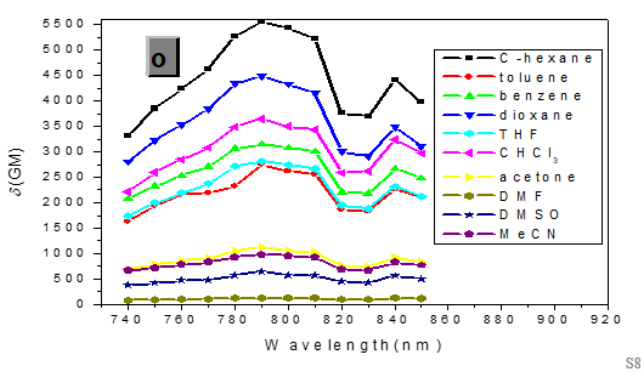

Figure 10: Two-photon absorption cross sections of $1 \mathrm{a}\left(\mathrm{c}=10^{-5} \mathrm{M}\right)$ in various solvents versus two-photon excited wavelengths.
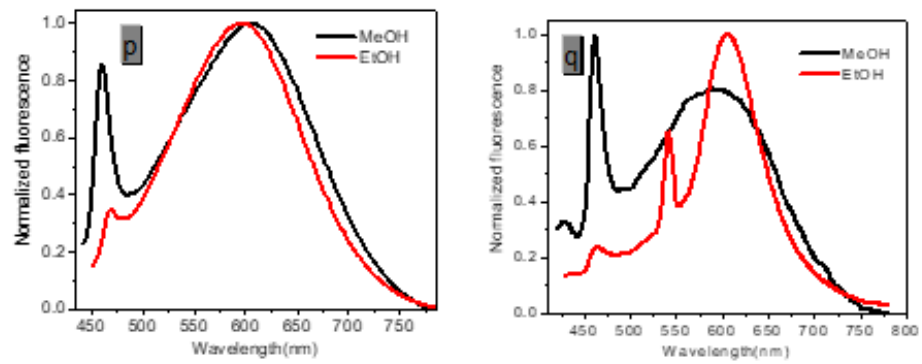

Figure 11: Normalized $(p)$ one- $(\lambda e x=410 \mathrm{~nm})$ and $(q)$ two-photon $(\lambda e x=790 \mathrm{~nm})$ emission spectra of 1a $(c=10-5 \mathrm{M})$ in $\mathrm{MeOH}$ and EtOH. One-photon emission maxima in $\mathrm{MeOH}$ and $\mathrm{EtOH}$ are 605 and $597 \mathrm{~nm}$ respectively.
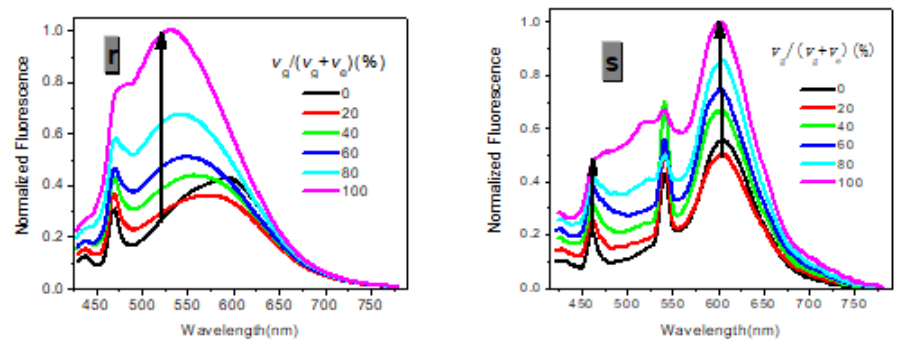

Figure 12: Normalized $(r)$ one- $\left(\lambda_{e x}=412 \mathrm{~nm}\right)$ and $(s)$ two-photon $\left(\lambda_{\mathrm{ex}}=810 \mathrm{~nm}\right)$ emission spectra of $1 \mathrm{~b}(\mathrm{c}=10-6 \mathrm{M})$ in glycerol-ethanol $\left(\mathrm{v}_{\mathrm{g}} \mathrm{g}^{\mathrm{s}}\right.$ $\left.\left(v_{g}+v_{e}\right), \%\right)$. 

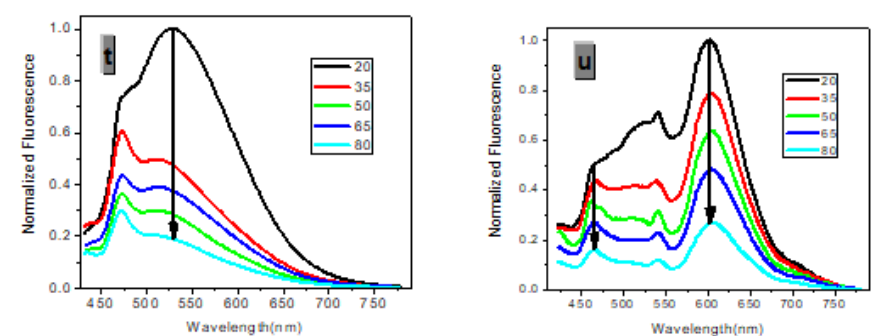

Figure 13: Normalized (t) one- $\left(\lambda_{e x}=410 \mathrm{~nm}\right)$ and $(\mathrm{u})$ two-photon $\left(\lambda_{\mathrm{ex}}=790 \mathrm{~nm}\right)$ emission spectra of $1 \mathrm{~b}\left(\mathrm{c}=10^{-6} \mathrm{M}\right)$ in glycerol versus temperature $\left({ }^{\circ} \mathrm{C}\right)$

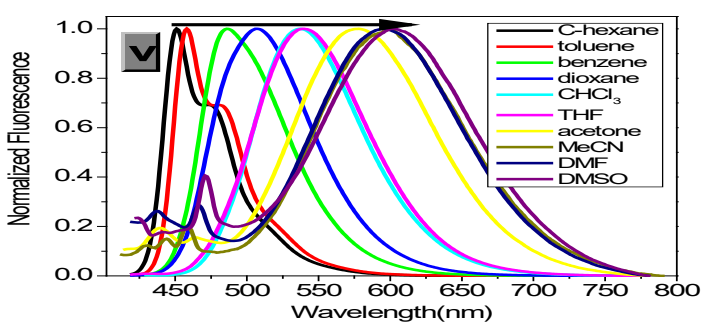

Figure 14: Normalized one-photon emission spectra of $1 \mathrm{~b}\left(\mathrm{c}=10^{-6} \mathrm{M}, \lambda_{\mathrm{ex}}=412 \mathrm{~nm}\right)$ in various solvents.

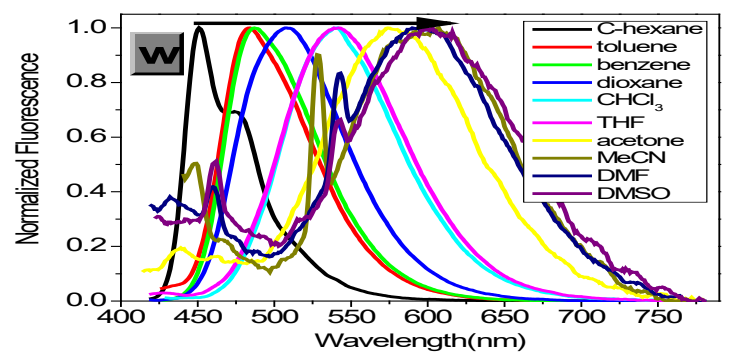

Figure 15: Normalized two-photon emission spectra of $1 \mathrm{~b}\left(\mathrm{c}=10^{-6} \mathrm{M}, \lambda_{\mathrm{ex}}=810 \mathrm{~nm}\right)$ in various solvents.

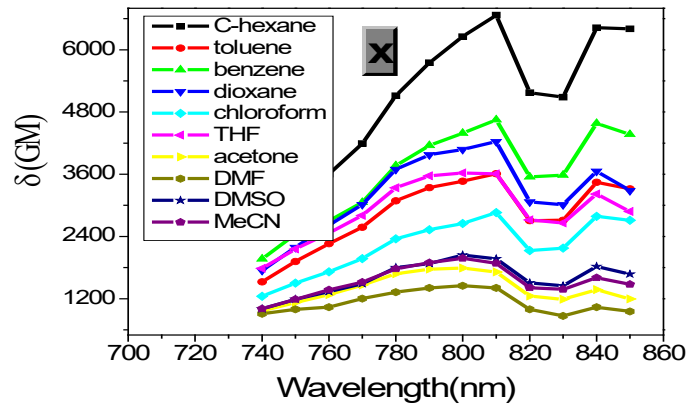

Figure 16: Two-photon absorption cross sections of $1 \mathrm{~b}\left(\mathrm{c}=10^{-6} \mathrm{M}\right)$ in various solvents versus two-photon excited wavelengths.

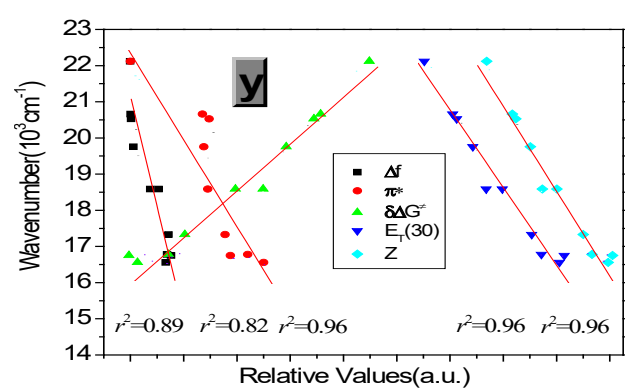

Figure 17:Correlation between the emission maxima (in $\mathrm{cm}-1$ ) of $1 \mathrm{~b}\left(\mathrm{c}=10^{-6} \mathrm{M}, \lambda_{\mathrm{ex}}=412 \mathrm{~nm}\right.$ ) in various solvents and selected solvent parameters such as $\Delta f, \pi^{*}, \delta \Delta G \neq, E_{T}(30)$ and $Z$. 


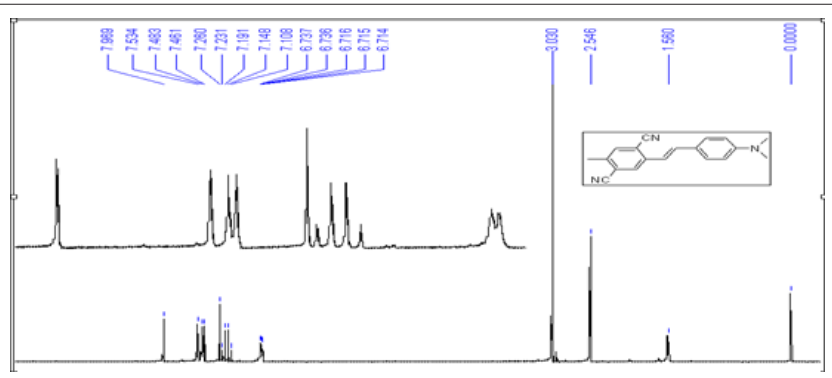

Figure 18: ${ }^{1} \mathrm{H}$ NMR spectrum for probe $1 \mathrm{a}$.

Figure 19: ${ }^{13} \mathrm{C}$ NMR spectrum for probe $1 \mathrm{a}$
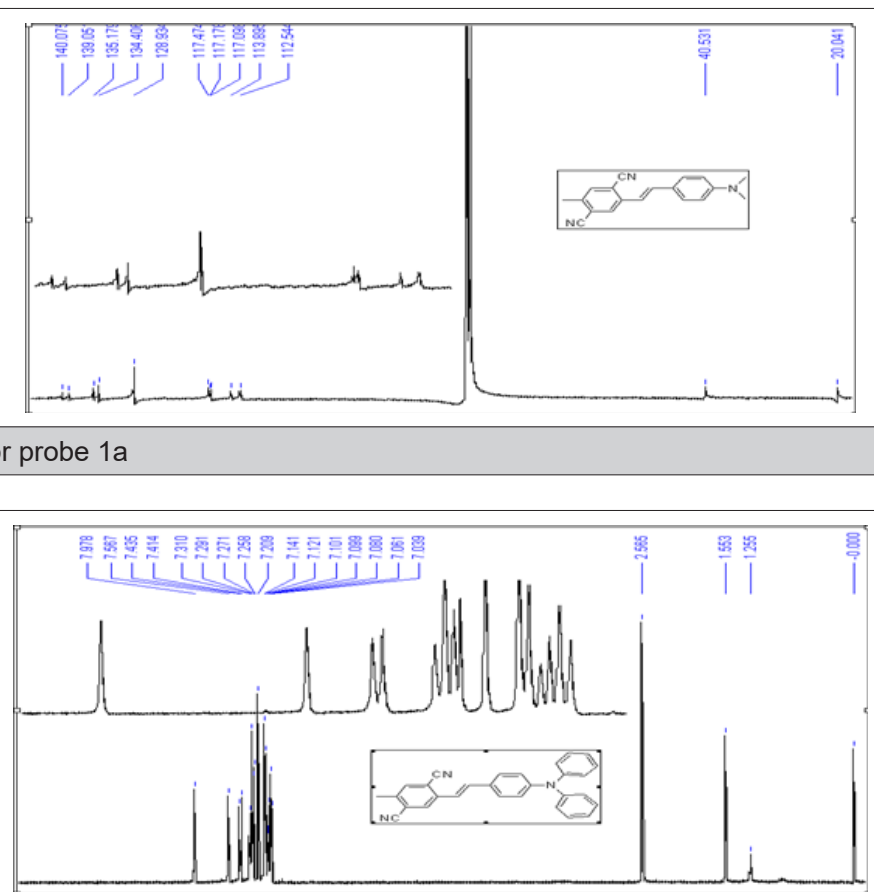

Figure 20: ${ }^{1} \mathrm{H}$ NMR spectrum for probe $1 \mathrm{~b}$

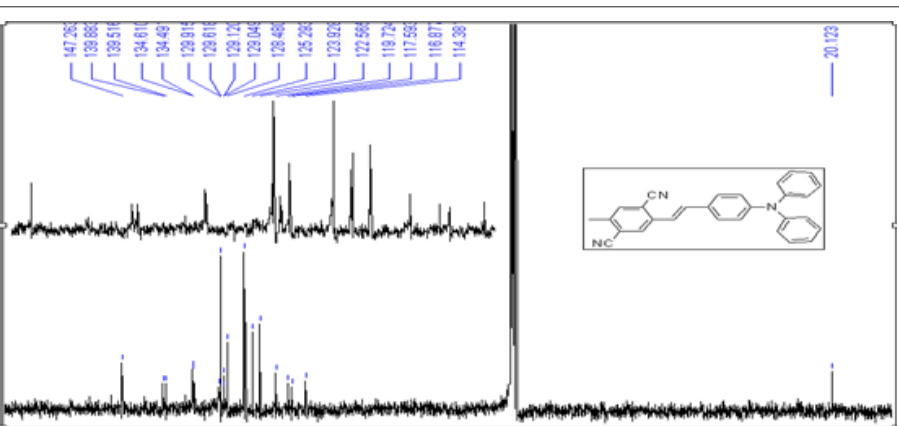

Figure $21:{ }^{13} \mathrm{C}$ NMR spectrum for probe $1 \mathrm{~b}$
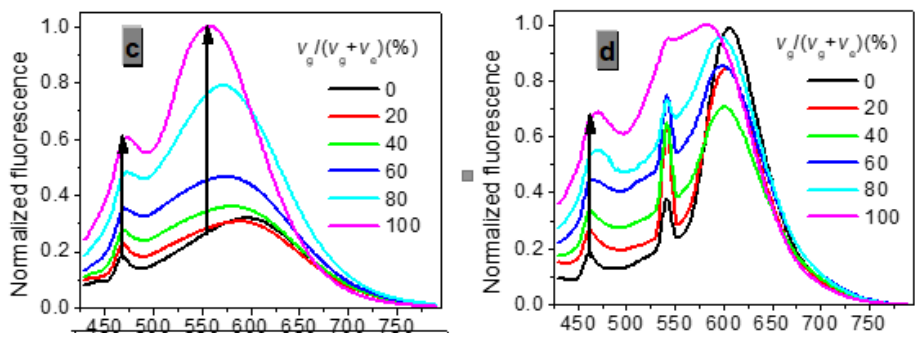

Figure 22: of $\mathrm{P} 1\left(\mathrm{c}=10^{-6} \mathrm{M}, \lambda_{\mathrm{ex}}(\mathrm{OP})=410 \mathrm{~nm}, \lambda_{\mathrm{ex}}(\mathrm{TP})=790 \mathrm{~nm}\right)$ in glycerol versus temperature $(\square)$ 


\section{Conclusion}

In conclusion, we have shown that the covalent attachment of two cyano groups in the single aromatic ring and dimethylamino group to stilbene is an considerably ingenious strategy, which makes the molecule a highly sensitive two-photon thermo-solvatochromic probe with remarkably large $\delta$ TPA and very high fluorescence quantum yield capable of being used to detect the analytes with high $\pi^{*}$, and to detect polarities, viscosities, and temperature. It was the first time that TP triple fluorescence was sighted in our compounds.

\section{References}

1. Bohne C, Ihmels H, Waidelich M, Yihwa C (2005) N-Acylureido functionality as acceptor substituent in solvatochromic fluorescence probes: detection of carboxylic acids, alcohols, and fluoride ions. J Am Chem 127(49): 17158-17159.

2. Droumaguet CL, Mongin O, Werts MHV, Blanchard Desce M (2005) Towards "smart" multiphoton fluorophores: strongly solvatochromic probes for two-photon sensing of micropolarity. Chemical Communications 22. 2(b). Strehmel B, Sarker AM, Detert H (2003) The influence of sigma and pi acceptors on two-photon absorption and solvatochromism of dipolar and quadrupolar unsaturated organic compounds. Chemphyschem 4(3): 249-259.

3. Kim HM, Jeong BH, Hyon JY, An MJ, Seo MS, et al. (2008) J Am Chem Soc 130: 4246. 3(b) Kim HM, Choo HJ, Jung SY, Ko YG, Park WH, et al. (2007) A two-photon fluorescent probe for lipid raft imaging: C-laurdan. ChemBioChem 8(5): 553-559.

4. Huang C, Ding C (2011) Analytica Chimica Acta. 3(b) Huang C, Qu J, Qi J, Yan M, Xu G (2011) Org Lett 13(6): 1462. 3(c) Huang C, Ren A, Feng C, Yang N (2010) Sensors and Actuators B: Chemical 151(1): 236. 3(d) Huang C, Fan J, Peng X, Lin Z, Guo B, et al. (2008) Photochem Photobiol 199: 144.

5. Bent D V, Sohulte Frohlinde D, (1974) J Phys Chem 28: 446. 5(b) Schanze KS, Shin DM, Whitten DG, (1985) J Am Chem Soc 107: 507. 5(c)Shin
DM, Whitten DG, (1988) J Phys Chem 92: 2945. 5(d) Lewis FD, Sinks LE, Weigel W, Sajimon MC, Crompton EM, (2005) J Phys Chem A 109: 2443. 5(e) Jager WF, Volkers AA, Neckers DC, (1995) Macromolecules 28: 8153.

6. Reichardt C (1994) Solvatochromic Dyes as Solvent Polarity Indicators. Chem Rev 94(8): 2319-2358.

7. Kbamlet MJ, Abboud JLM, Taft RW (1981) Progress in Physical Organic Chemistry 13: 485.

8. Lippert EZ (1955) Naturforsch A 10: 541. 8(b) Mataga N, Kaifu Y, Koizumi M (1956) Bull Chem Soc Jpn 29: 465.

9. Knibbe H, Rollig K, Schifer FP, Weller A (1967) J Chem Phys 47: 1184. (b) Knibbe H, Rehm D, Weller A (1968) Ber Bunsen-Ges Phys Chem 72: 257. (c) Weller AZ (1982) Phys. Chem. (Wiesbaden) 133: 93.

10. Khalil OS (1975) Chem Phy Lett 35: 172.

11. Collins GE, Choi LS, Callahan JH (1998) J Am Chem Soc 120: 1474.

12. Kamlet MJ, Abboud JL, Taft RW (1977) The solvatochromic comparison method. 6. The. pi. * scale of solvent polarities. J Am Chem Soc 99(18): 6027.6038

13. Retting W Angew (1986) Chem Int Ed Engl pp. 971.

14. Eaton DF (1988) International union of pure and applied chemistry organic chemistry division commission on photochemistry: Reference materials for fluorescence measurement. Journal of Photochemistry and Photobiology B: Biology 2(4): 523-531.

15. Xu C, Webb WW (1996) Measurement of two-photon excitation cross sections of molecular fluorophores with data from 690 to $1050 \mathrm{~nm}$. Journal of the Optical Society of America B 13(3): 481-491.

16. Huang H, He Q, Lin H, Fenglian Bai, Zhi Sun, et al. (2004) Polymers advanced technologies 15(1-2): 84-88.

17. Baker TN, Doherty WP, Kelley WS, Newmeyer W, Rogers JE, et al. (1965) J Org Chem 30: 3714-3718. 